\title{
Etiologic Agents and Diseases Found Associated with Clinical Aspergillosis in Falcons
}

\author{
Walter Tarello \\ Division of Avian \& Exotic, Pet Connection Veterinary Clinic, P.O. Box 450288, Dubai, UAE \\ Correspondence should be addressed to Walter Tarello, wtarello@yahoo.it
}

Received 14 February 2011; Accepted 19 April 2011

Academic Editor: Todd R. Callaway

Copyright () 2011 Walter Tarello. This is an open access article distributed under the Creative Commons Attribution License, which permits unrestricted use, distribution, and reproduction in any medium, provided the original work is properly cited.

The aim of this study was to describe parasitological, microbiological, and pathological findings associated with the isolation of Aspergillus species in 94 clinically diseased captive falcons from Dubai. Concomitant agents and/or diseases were identified in 64 cases, causing either single $(n=36)$ or multiple coinfections $(n=28)$. Diagnoses found more often in association with aspergillosis were chronic fatigue and immune dysfunction syndrome (CFIDS) $(n=29)$, Caryospora sp. $(n=16)$, Serratospiculum seurati infestation $(n=14)$, cestodiasis $(n=6)$, bumblefoot $(n=5)$, trematodosis due to Strigea falconispalumbi $(n=5)$, trichomoniasis $(n=4)$, Babesia shortti $(n=4)$, Mannheimia (Pastorella) haemolytica $(n=4)$, interstitial hepatitis $(n=4)$, Escherichia coli $(n=3)$, and Clostridium perfringens enterotoxemia $(n=2)$. Compared with a control group of 2000 diseased falcons without evidence of aspergillosis, the prevalence of Babesia shortti, CFIDS, Mannheimia (Pastorella) haemolytica, Escherichia coli, and falcon herpes virus infection was conspicuously higher in association with aspergillosis. These entities may be considered suitable candidates as predisposing factors for the mycosis.

\section{Introduction}

Aspergillosis is considered the most common systemic mycosis in birds [1] and the most important cause of death in captive falcons [2,3]. Infections with Aspergillus fumigatus and, less commonly, with A. flavus, A. terreus, and A. niger apparently share the same clinical importance in raptors held in captivity [4]. Clinical signs in birds are nonspecific and include reduction in appetite, weight loss, dyspnoea, lethargy, and death [5].

Avian aspergillosis involves mainly the lower respiratory tract [6]. This also occurs in falcons, in which the majority of reported cases are isolated from the air sacs [4]. These fungi are ubiquitous, but they become pathogenic mainly under stressful conditions, producing opportunistic infections as a result of inhalation of Aspergillus spores coupled with compromised immune functions in the host or in association with prolonged diseases [6-8]. Poor ventilation, malnutrition, toxins, vaccinations, long-term use of antibiotics and corticosteroids, hot-humid climate, and stress-associated conditions, such as recent capture, training, and change of ownership, are frequently mentioned as environmental precipitating factors influencing the onset and duration of aspergillosis in falcons [7-10].

Unfortunately, what actually causes immunosuppression and/or prolonged disease is rarely mentioned in the literature, because dual or multiple infections with potentially immunocompromising or chronically persistent pathogens (i.e., Mycobacterium spp., Babesia shortti, and Serratospiculum sp. nematode) are only sporadically recorded in raptors $[11,12]$ and other birds with aspergillosis $[8,13]$. It is not clear whether these infections are truly rare, underdiagnosed, diagnosed but underestimated, or simply rarely reported.

Thus, it seemed important to assess to what extent the involvement of concurrent agents occurs in the condition. This study provides a list of the pathogens recorded recently in 94 captive falcons from Dubai with a definitive diagnosis of aspergillosis and compares their prevalence with a control group of 2000 randomly chosen diseased falcons without clinical, biochemical, and endoscopic evidence of aspergillosis. 


\section{Materials and Methods}

The study was carried out at the Al Wasl Veterinary Clinic, Dubai, United Arab Emirates, from August 2005 to October 2006. Biopsy samples were collected during endoscopy from the air sacs of 94 diseased falcons diagnosed with fungal disease of the lower respiratory tract and showing compatible clinical signs. There were 30 gyrfalcons (Falco rusticolus), 19 saker falcons (Falco cherrug), 12 peregrine falcons (Falco peregrinus), 2 Barbary falcons (Falco pelegrinoides), and 31 hybrid falcons. Specimens were cultured in Sabouraud's chloramphenicol agar (bioMerieux) and incubated at $37^{\circ} \mathrm{C}$ for three to five days. Ninety-six fungal isolates were collected from 94 falcons. The species involved were identified, on the basis of macroscopic appearance of cultures and their microscopic morphological features, after staining with lactophenol aniline, as follow: Aspergillus fumigatus (57 cases), A. flavus (13 cases), A. terreus (12 cases), A. niger (10 cases), A. niger + A. flavus ( 1 case), and A. niger + A. fumigatus (1 case). Information evaluated included signalment, duration of the disease, clinical signs, concurrent diseases, and previous diagnosis and treatments.

Treatment for aspergillosis was based on antifungal medicaments, such as amphotericin B, itraconazole, and voriconazole.

Blood samples of $1.5 \mathrm{~mL}$ were collected from the medial metatarsal vein and used for the preparation of Wrightstained blood smears and for routine biochemical and hematological tests. Microscopic search of parasite eggs was performed on fresh feces. Samples for bacteriology and virology tests were collected with sterile swabs from crop, trachea, air sacs, and cloaca in selected cases and sent to the Central Veterinary Research Laboratory (CVRL) of Dubai. In some cases, kidney and liver biopsies as well as carcasses were also sent to the CVRL for histopathology and postmortem examination. The prevalence of concurrent diseases and/or agents was compared with those of a control group of 2000 randomly chosen diseased falcons without clinical, biochemical, and endoscopic evidence of aspergillosis examined in the Al Wasl Veterinary Clinic, Dubai, during the same period.

\section{Results}

Concomitant agents and/or diseases were identified in 64 cases, causing either single $(n=36)$ or multiple coinfections $(n=28)$, and these are listed in Table 1. Death occurred in 16 cases (Table 1 ).

The most commonly associated parasitic diseases were coccidiosis due to Caryospora spp. infection $(n=16)$ and Serratospiculum seurati $(n=14)$. Infestations with the trematode Strigea falconispalumbi $(n=5)$ and Capillaria spp. $(n=1)$ were found only associated with A. flavus infection, as well as one fatal case of leucocytozoonosis.

Trichomoniasis $(n=4)$ was mostly associated with $A$. fumigatus $(n=3)$. Viral diseases identified in the study group were falcon herpes virus $(n=2)$ and pox virus $(n=$ 2) infection.
The most commonly diagnosed bacterial diseases were the chronic fatigue and immune dysfunction syndrome (CFIDS) $(n=29)$ [14], bumblefoot or pododermatitis $(n=$ 5), Mannheimia (Pastorella) haemolytica $(n=4)$, Escherichia coli $(n=3)$, and Clostridium perfringens enterotoxemia $(n=$ 2). Concurrent CFIDS and bumblefoot were diagnosed in 2 out of five cases of pododermatitis associated with aspergillosis, apparently confirming the link previously noted between the two conditions [15].

Fatal outcomes were mostly seen associated with CFIDS $(n=4)$, pastorellosis $(n=2)$, herpes virus infection $(n=$ $2)$, and amyloidosis $(n=2)$. Two fatal cases of Aspergillus fumigatus infection were associated with CFIDS and in vivo resistance to long-term treatment with voriconazole.

Comparison between prevalence of concurrent diseases and/or agents found in diseased falcons with $(n=94)$ and without aspergillosis $(n=2000)$ shows that Babesia shortti, CFIDS, Mannheimia haemolytica, Escherichia coli, and falcon herpes virus infection are significantly more common in birds with aspergillosis (Table 2).

\section{Discussion}

Aspergillus fumigatus is one of the major clinical isolates in falcons with aspergillosis [16]. Results reported here confirm such prevalence, because $58(60 \%)$ of the recorded cases were due to A. fumigatus. Infections with A. flavus $(n=14)$, A. terreus $(n=12)$, and A. niger $(n=12)$ were also common. In this study, concomitant primary pathogenic agents and/or diseases were identified in approximately $2 / 3$ of the Aspergillus-positive falcon cases (Table 1), 1/3 of which showed multiple coinfections, thus apparently confirming the claimed opportunistic role of aspergillosis.

However, in most cases, this assumption proved incorrect when the prevalence rates of the etiologic agents involved were compared with those reported in a large group of diseased falcons $(n=2000)$ without aspergillosis. In fact, the recorded rates of Caryospora spp., Serratospiculum seurati, Strigea falconispalumbi, candidosis, capillariasis, leucocytozoonosis, bumblefoot, Clostridium perfringens enterotoxaemia, and pox virus infection do not substantially differ between the 2 groups (Table 2). Furthermore, and curiously, cestodiasis and trichomoniasis are significantly less prevalent in falcons with aspergillosis (Table 2).

Therefore, these agents do not constitute a risk factor in the development of aspergillosis in falcons, as well as other bacteria less commonly encountered such as Klebsiella ozanonae $(n=1)$, Moraxella sp. $(n=1)$, Staphylococcus aureus $(n=1)$, and Acinetobacter baumannii $(n=1)$, occasionally associated with aspergillosis (Table 1). Candidosis was diagnosed once in association with A. fumigatus infection. This is one of the most common fungal diseases in birds [17]. The low prevalence recorded in this study seems at least unusual, and it is probably due to underdiagnosis. Previous association between Candida and Aspergillus has been described in 2 Amazon parakeets [13].

Why Babesia shortti, CFIDS, Mannheimia (Pastorella) haemolytica, Escherichia coli, and falcon herpes virus infections were notably more common in birds with aspergillosis 
TABLE 1: Etiologic agents and diseases found associated with aspergillosis in falcons.

\begin{tabular}{|c|c|c|c|c|c|c|}
\hline \multirow{3}{*}{ Concurrent diseases } & \multicolumn{4}{|c|}{ Aspergillus isolates } & \multirow{3}{*}{$\begin{array}{c}\text { Total } \\
96\end{array}$} & \multirow{3}{*}{$\begin{array}{c}\text { Deaths } \\
16\end{array}$} \\
\hline & A. fumigatus & A. flavus & A. terreus & A. niger & & \\
\hline & 58 isolates & 14 isolates & 12 isolates & 12 isolates & & \\
\hline \multicolumn{7}{|l|}{ Parasites } \\
\hline Caryospora spp. & 7 & 4 & 1 & 4 & 16 & - \\
\hline Serratospiculum spp. & 7 & 1 & 1 & 5 & 14 & 1 \\
\hline Cestodes & 1 & 1 & 1 & 3 & 6 & - \\
\hline Trematodes (S. falconis) & - & 5 & - & - & 5 & 1 \\
\hline Trichomoniasis & 3 & 1 & - & - & 4 & - \\
\hline Babesia shortti & 1 & 2 & - & 1 & 4 & - \\
\hline Candidosis & 1 & - & - & - & 1 & - \\
\hline Capillaria spp. & - & 1 & - & - & 1 & - \\
\hline Leucocytozoon toddi & - & 1 & - & - & 1 & 1 \\
\hline \multicolumn{7}{|l|}{ Bacteria } \\
\hline (CFIDS) & 17 & 4 & 6 & 2 & 29 & 4 \\
\hline Bumblefoot & 3 & 1 & - & 1 & 5 & - \\
\hline Mannheimia haemolytica & 1 & 2 & - & 1 & 4 & 2 \\
\hline Escherichia coli & 1 & 1 & - & 1 & 3 & 1 \\
\hline Clostridium perfringens & 1 & - & 1 & - & 2 & 1 \\
\hline Klebsiella ozanonae & 1 & - & - & - & 1 & - \\
\hline Moraxella sp. & - & 1 & - & - & 1 & - \\
\hline Staphylococcus aureus & - & - & 1 & - & 1 & - \\
\hline Acinetobacter baumannii & - & - & - & 1 & 1 & - \\
\hline Ehrlichiosis & 0 & 1 & 0 & 0 & 1 & - \\
\hline \multicolumn{7}{|l|}{ Virus } \\
\hline Falcon herpes virus & 1 & - & 1 & - & 2 & 2 \\
\hline Pox virus & 1 & - & - & 1 & 2 & 1 \\
\hline \multicolumn{7}{|l|}{ Other diseases } \\
\hline Interstitial hepatitis & 2 & 2 & - & - & 4 & - \\
\hline Amyloidosis & 1 & - & - & 1 & 2 & 2 \\
\hline Chronic nephritis & - & - & 1 & - & 1 & - \\
\hline
\end{tabular}

(Table 2)? Do they really constitute predisposing factors for the mycotic disease or are they simply the result of mistaken overdiagnosis?

We should remember first that in human medicine, underlying diseases favouring Aspergillus are relatively well known and are the followings: hematological malignancies $(33 \%)$, chronic obstructive pulmonary disease $(22 \%)$, bone marrow transplant (14\%), HIV infection $(11 \%)$, and absolute neutropenia (10\%) [18]. Hematological malignancies are rarely described in falcons and not in association with aspergillosis [19]. With the exclusion of cancer, it is acknowledged in veterinary medicine that aspergillosis generally occurs mainly in immune-compromised hosts [10].

Babesiosis is recognized as an immune-compromising disease [20]. In this study, Babesia shortti was diagnosed in 4 chronically ill falcons [21] with aspergillosis (1 A. fumigatus, 2 A. flavus, and 1 A. niger). Clinical manifestation of babesiosis varies from subclinical signs in apparently healthy animals with low parasitaemia to severe disease associated with high parasitaemia, showing weight loss, anorexia, lethargy, vomiting, seizure, and blood in the stool [21]. These signs are nonspecific and overlapping those of aspergillosis in most cases. Recently, the first molecular characterization of the organisms revealed that Babesia shortti is closely related (97\%) to Babesia poelea, recently described in Brown boobies (Sula leucogaster), and that it belongs to the clade of piroplasms previously detected in humans, dogs, and wild ungulates in the western United States [22]. Canine babesiosis is known to cause immune dysfunctions which favour secondary opportunistic infections [23, 24]. Previous report of concomitant occurrence of B. shortti and A. fumigatus leading to fatal outcomes [12] agrees with the hypothesis supported here that babesiosis tends to predispose and exacerbate the mycotic disease.

In this study, the isolation of herpes virus in two fatal cases of falcon hepatitis with concomitant aspergillosis (A. fumigatus and A. terreus) is probably the first occurrence of such association recorded in veterinary literature. 
TABLE 2: Comparison between prevalences of aetiologic agents and diseases found in falcons with and without aspergillosis.

\begin{tabular}{|c|c|c|c|c|c|}
\hline \multirow{2}{*}{ Agent/Disease } & \multicolumn{2}{|c|}{ With aspergillosis } & & \multicolumn{2}{|c|}{ Without aspergillosis } \\
\hline & $(n=94)$ & $\%$ & & $(n=2000)$ & $\%$ \\
\hline \multicolumn{6}{|l|}{ Parasites } \\
\hline Caryospora spp. & (16) & 17.00 & $\sim$ & $(317)$ & 15.80 \\
\hline Serratospiculum seurati & (14) & 14.90 & $\sim$ & $(253)$ & 12.65 \\
\hline Cestodes & (6) & 6.38 & $<$ & $(163)$ & 8.15 \\
\hline Trematodes & (5) & 5.32 & $\sim$ & $(101)$ & 5.05 \\
\hline Trichomoniasis & (4) & 4.25 & $<$ & $(148)$ & 7.40 \\
\hline Babesia shortti & (4) & 4.25 & $>$ & $(22)$ & 1.10 \\
\hline Candidosis & (1) & 1.06 & $\sim$ & (13) & 0.65 \\
\hline Capillaria spp. & (1) & 1.06 & $\sim$ & $(31)$ & 1.55 \\
\hline Leucocytozoon toddi & (1) & 1.06 & $\sim$ & $(16)$ & 0.80 \\
\hline \multicolumn{6}{|l|}{ Bacteria } \\
\hline CFIDS & (29) & 30.85 & $>$ & $(240)$ & 12.00 \\
\hline Bumblefoot & (5) & 5.32 & $\sim$ & $(81)$ & 4.05 \\
\hline Mannheimia haemolytica & (4) & 4.25 & $>$ & (2) & 0.10 \\
\hline Escherichia coli & (3) & 3.12 & $>$ & $(20)$ & 1.00 \\
\hline Clostridium perfringens & (2) & 2.13 & $\sim$ & (29) & 1.45 \\
\hline \multicolumn{6}{|l|}{ Viruses } \\
\hline Falcon herpes virus & (2) & 2.13 & $>$ & (6) & 0.30 \\
\hline Pox virus & (2) & 2.13 & $\sim$ & $(44)$ & 2.20 \\
\hline
\end{tabular}

Identification of the causative virus was done postmortem. It is not excluded that more cases of herpes virus infection might have been missed, lacking a specific suspect and/or fatal outcomes.

Mannheimia (Pastorella) haemolytica, a Gram-negative highly pathogenic bacterium causative agent of the pneumonic pastorellosis, was associated with 4 cases of aspergillosis in this study ( 1 A. fumigatus, 2 A. flavus, and 1 A. niger), 2 of which showing fatal outcomes despite aggressive antifungal therapy. Table 2 shows that $M$. haemolytica was strikingly more prevalent in falcons with aspergillosis (4.25\%) when compared with the control group $(0.1 \%)$ apparently indicating a predisposing action for the mycotic disease. Clinical signs of avian pastorellosis, such as general malaise, respiratory distress, and diarrhea [25], are vague and partially overlapping those due to aspergillosis. Lack of recognition and of preventive treatment for underlying pastorellosis may lead to poor prognosis and negative therapy outcomes for the concomitant aspergillosis. The same should apply to Escherichia coli ( $n=3,1$ death) (Table 1), which was prevalently found associated with aspergillosis $(3.12 \%$ versus $1 \%$ ) in this study (Table 2 ). These bacteria are potentially pathogenic for falcons [25], causing chronic diseases and immune dysfunctions that can predispose to aspergillosis and complicate its therapy. Aspergillus sp. association with Pastorella multocida has been previously described in turkeys [1].

In human medicine, aspergillosis also occurs as an opportunistic infection in the condition named idiopatic CD4+ T lymphocytopenia $[26,27]$, a subtype of the chronic fatigue syndrome (CFS), also called chronic fatigue and immune dysfunction syndrome (CFIDS) due to the frequency with which autoimmune defects and cellular and humoral deficiencies are recorded in human and animal patients as well [28]. It is acknowledged that about $1 / 10$ of human CFIDS patients shift naturally to the condition called idiopathic CD4+ T cell lymphocytopenia (ICL), which is characterized by decreased CD4+ T cells count in the absence of HIV infection and occasional association with leukopenia and pan-hypogammaglobulinemia. Most cases of ICL, also called HIV-negative AIDS, fulfil the CDC criteria for CFIDS, and the two conditions appear today as variations in severity of a single disease [28]. Immunological anomalies such as leukopenia, lymphopenia, and hypogammaglobulinemia have been seen in birds of prey [14] and dogs and cats previously diagnosed with CFIDS [28]. It is comparatively interesting to note that CFIDS in this study was the underlying disease most commonly diagnosed in captive falcons with proved aspergillosis (29 reported cases and 4 deaths). In my experience, CFIDS is associated with staphylococcal infection and bacteraemia in birds of prey [14] and other animals [28-34]. The prevalence reported here should not be controversial because the prevalence of Staphylococcus spp. infections in the Spanish imperial eagle (Aquila adalberti) was as high as $45 \%$ in chicks handled without gloves, and $4 \%$ in chicks handled with gloves [35]. Apparently, the humananimal contact was the way of transmission. Reported captive falcons diagnosed with CFIDS are routinely subjected to human-animal interaction, intense training, and, therefore, oxidative stress, that favour CFIDS [31].

Conditioned illnesses are difficult to treat when underlying primary agents are not preliminarily eliminated [24]. As 
a confirmation, two fatal cases of A. fumigatus infection associated with CFIDS showed in vivo resistance to voriconazole, currently considered the best antifungal agent available on the market [4].

CFIDS was diagnosed on the basis of the presence of micrococci in the circulating blood, as detected on Wrightstained blood smears by light microscopy, high creatine kinase levels, and suggestive clinical signs, such as weight loss, lethargy, poor appetite, and reduced speed and strength in flight $[14,29]$. The micrococcal forms observed in the blood were indistinguishable from those previously seen in birds of prey diagnosed with CFIDS [14]. The condition, also called chronic fatigue syndrome (CFS), can affect a variety of species, including humans [30-34] and falcons [29]. In this author experience, detection of micrococci in blood smears seems to be a diagnostic criterion for CFIDS diagnosis in many species [30-34], being the most remarkable haematological difference between chronically fatigued and healthy patients and by revealing the association with an underlying Staphylococcus spp. bacteraemia [28]. Blood cultures are less sensitive [30-34] due to a wide range of factors affecting the growth of bacteria from blood samples, including plate's contamination. Therefore, blood cultures were not performed in the present case series. In a number of animal and human CFS cases reported till now, blood cultures proved nonetheless positive for the growth of strains of Staphylococcus intermedius, S. xylosus, S. epidermidis, St. lugdunensis, S. cohnii, S. warneri, and S. chromogenes [3034] confirming that the micrococci seen in the blood smears actually were coagulase-negative staphylococci invading the bloodstream.

Today, these staphylococci are not considered benign as previously thought, since they can also cause meningoencephalitis in dogs and human beings [36]. Toxin-secreting staphylococci produce a group of proteins called superantigens, which are toxins capable of inducing a polyclonal T-cell activation and high interleukin-2 secretion. In the long run, this mechanism may induce autoimmunity, stimulating the growth of a subset of lymphocytes that recognize the "self" as a stranger. Such nonspecific activation can also lead to immune deficiency because certain T-cells subpopulations vigorously proliferate and finally die, leaving an open door to opportunistic agents [28], such as Aspergillus species.

CFIDS is not widely known to occur in animals and consequently was not considered, up to now, a possible concurrent and/or favoring agent for aspergillosis. In human medicine, CFIDS is perceived as underdiagnosed [31]. The general lack of CFIDS diagnosis in veterinary medicine should not be regarded as evidence of absence and for excluding CFIDS as a true predisposing factor for aspergillosis, considering that these bacteria are difficult to isolate and their presence in the host is not obvious [36]. Antifungal therapy is usually unsuccessful in chronic, advanced cases of aspergillosis [6] suggesting that an early therapy for aspergillosis (and for concurrent agents) would be appropriate in most cases. It is acknowledged that in conditioned illnesses the eradication of concurrent pathogens is a prerequisite for an effective therapy [24]. Little information is available about the effectiveness of antifungal drugs in multiple infections. Resistance to voriconazole and itraconazole has been reported in Aspergillus species in vitro, and decreased susceptibility has been noticed recently in Aspergillus sp. to multiple antifungal agents [37]. If this is linked to the presence of concurrent pathogens, it is hard to say at present time and should be further evaluated. Aspergillosis seems uncommon in the wild [38]. On the contrary, it is common in captive and domesticated conditions [5], indicating that environmental factors, including human manipulation ensuing potential transmission of concurrent favoring pathogens, also play their role. To which extent external factors influence the course of aspergillosis in falcons is difficult to determine quantitatively. Minimizing stress and nutritional factors does not eliminate aspergillosis when it is established. Recovery of potentially synergic or feasibly immunosuppressive agents in falcons with aspergillosis should be considered a step toward a better understanding of the pathogenesis of the mycosis.

\section{Acknowledgment}

The author thanks the staff at the Central Veterinary Research Laboratory (CVRL), Dubai (UAE), for processing the biological samples submitted for postmortem, histopathological, bacteriological, and virological examinations.

\section{References}

[1] R. A. Kunkle and R. B. Rimler, "Early pulmonary lesions in turkeys produced by nonviable Aspergillus fumigatus and/or Pasteurella multocida lipopolysaccharide," Avian Diseases, vol. 42, no. 4, pp. 770-780, 1998.

[2] J. E. Cooper, Veterinary Aspects of Captive Birds of Prey, Standfast Press, Cherington, UK, 2nd edition, 1985.

[3] J. H. Samour, "Veterinary considerations during the hunting trip," in Raptor Biomedicine III, J. T. Lumeij, J. D. Remple, P. T. Redig, M. Lierz, and J. E. Cooper, Eds., pp. 267-274, Zoological Education Network, Lake Worth, Fla, USA, 2000.

[4] C. D. Silvanose, T. A. Bailey, and A. Di Somma, "Susceptibility of fungi isolated from the respiratory tract of falcons to amphotericin B, itraconazole and voriconazole," Veterinary Record, vol. 159, no. 9, pp. 282-284, 2006.

[5] J. Pérez, P. M. García, A. Méndez, R. Astorga, I. Luque, and C. Tarradas, "Outbreak of aspergillosis in a flock of adult ostriches (Struthio camelus)," Veterinary Record, vol. 153, no. 4, pp. 124-125, 2003.

[6] T. N. Campbell, "Mycotic diseases," in Clinical Avian Medicine and Surgery, G. J. Harrison and L. R. Harrison, Eds., vol. 986, pp. 464-466, W.B. Saunders, Philadelphia, Pa, USA.

[7] S. L. Deem, "Fungal diseases of birds of prey," Veterinary Clinics of North America, vol. 6, no. 2, pp. 363-376, 2003.

[8] P. Redig, "Aspergillosis," in Avian Medicine, J. Samour, Ed., pp. 275-287, Elsevier Science Limited, Edimburgh, Scotland, 2003.

[9] S. Nardoni, R. Ceccherelli, G. Rossi, and F. Mancianti, "Aspergillosis in Larus cachinnans micaellis: survey of eight cases," Mycopathologia, vol. 161, no. 5, pp. 317-321, 2006.

[10] S. Mukaratirwa, "Outbreak of disseminated zygomycosis and concomitant pulmonary aspergillosis in breeder layer cockerels," Journal of Veterinary Medicine Series B, vol. 53, no. 1, pp. 51-53, 2006. 
[11] G. Kaliner and J. E. Cooper, "Dual infection of an African fish eagle with acid-fast bacilli and anAspergillus sp," Journal of Wildlife Diseases, vol. 9, no. 1, pp. 51-55, 1973.

[12] J. H. Samour and M. A. Peirce, "Babesia shortti infection in a saker falcon (Falco cherrug)," Veterinary Record, vol. 139, no. 7, pp. 167-168, 1996.

[13] L. Carrasco, J. C. Gómez-Villamandos, and H. E. Jensen, "Systemic candidosis and concomitant aspergillosis and zygomycosis in two Amazon parakeets (Amazona aestiva)," Mycoses, vol. 41, no. 7-8, pp. 297-301, 1998.

[14] W. Tarello, "Chronic fatigue and immune dysfunction syndrome associated with Staphylococcus spp. bacteraemia responsive to thiacetarsamide sodium in eight birds of prey," Journal of Veterinary Medicine, Series B, vol. 48, no. 4, pp. 267281, 2001.

[15] W. Tarello, "A possible relationship between bumblefoot responsive to potassium arsenite and micrococci in the blood of three birds of prey," Acta Veterinaria Hungarica, vol. 50, no. 2, pp. 143-150, 2002.

[16] R. Wernery, U. Wernery, J. Kinne, and J. Samour, Colour Atlas of Falcon Medicine, Hannover; Schlutersche Verlagsgesellschaft mBH \& Co, Berlin, Germany, 2004.

[17] C. Silvanose, "Candidiasis," in Avian Medicine, J. Samour, Ed., pp. 287-289, Elsevier Science Limited, Edimburgh, Scotland, 2003.

[18] F. Khasawneh, T. Mohamad, M. K. Moughrabieh, Z. Lai, J. Ager, and A. O. Soubani, "Isolation of Aspergillus in critically ill patients: a potential marker of poor outcome," Journal of Critical Care, vol. 21, no. 4, pp. 322-327, 2006.

[19] W. Tarello, "Lymphoid leukaemia in a saker falcon," Veterinary Record, vol. 158, no. 6, p. 212, 2006.

[20] A. C. Purvis, "Immunodepression in Babesia microti infections," Parasitology, vol. 75, no. 2, pp. 197-205, 1977.

[21] W. Tarello, "Effective imidocarb dipropionate therapy for Babesia shortti in falcons," Veterinary Record, vol. 158, no. 7, pp. 239-240, 2006.

[22] W. Tarello and M. J. Yabsley, "Is babesiosis in falcons more common than currently thought?" in Proceedings of the 9th European Association of Avian Veterinarians (EAAV) Conference, Zurich, Switzerland, March 2007.

[23] W. Tarello, "Babesiosis as an underlying factor influencing the severity and duration of perianal fistulas in three dogs," Revue de Médecine Vétérinaire, vol. 152, no. 1, pp. 83-88, 2001.

[24] W. Tarello, "Cutaneous lesions in dogs with Dirofilaria (Nochtiella) repens infestation and concurrent tick-borne transmitted diseases," Veterinary Dermatology, vol. 13, no. 5, pp. 267-274, 2002.

[25] P. Zwart, "Bacterial diseases," in Avian Medicine, J. Samour, Ed., pp. 252-263, Elsevier Science Limited, Edimburgh, Scotland, 2003.

[26] M. J. Van der Ven, J. W. Lenders, A. A. Baas, A. C. Holdrinet, and J. W. Van der Meer, "Idiopathic CD4+T lymphocytopenia," Nederlands Tijdschrift voor Geneeskunde, vol. 141, no. 6, pp. 298-301, 1997.

[27] M. Nakahira, S. Matsumoto, N. Mukushita, and H. Nakatani, "Primary aspergillosis of the larynx associated with CD4+T lymphocytopenia," Journal of Laryngology and Otology, vol. 116, no. 4, pp. 304-306, 2002.

[28] W. Tarello, "Immunological anomalies and thrombocytopenia in 117 dogs and cats diagnosed with Chronic Fatigue Syndrome (CFS)," Acta Veterinaria Hungarica, vol. 51, no. 1, pp. 61-72, 2003.

[29] W. Tarello, "Complete remission after treatment of Chronic Fatigue Syndrome (CFS) in 118 falcons using potassium arsenite $0.05 \%$," in Proceedings of the World Conference on Dosing of Anti-infectives (WCDA '04), p. 138, Nurnberg, Germany, September 2004.

[30] W. Tarello, "Chronic fatigue syndrome in horses: diagnosis and treatment of 3 cases," Vet On-Line, 2000, http://www.priory.com/vet/cfsdogs.htm.

[31] W. Tarello, "Chronic Fatigue Syndrome (CFS) associated with Staphylococcus spp. bacteremia, responsive to potassium arsenite $0.5 \%$ in a veterinary surgeon and his coworking wife, handling with CFS animal cases," Comparative Immunology, Microbiology \& Infectious Diseases, vol. 24, no. 4, pp. 233-246, 2001.

[32] W. Tarello, "Chronic Fatigue Syndrome (CFS) in 15 dogs and cats with specific biochemical and microbiological anomalies," Comparative Immunology, Microbiology \& Infectious Diseases, vol. 24, no. 3, pp. 165-185, 2001.

[33] W. Tarello, "Chronic fatigue syndrome (CFS) associated with Staphylococcus spp. bacteremia, responsive to thiacetarsamide sodium in 7 dogs," Revue de Médecine Vétérinaire, vol. 152, no. 11, pp. 785-792, 2001.

[34] W. Tarello, "Chronic fatigue syndrome (CFS) in cats : symptoms, diagnosis and treatment of 7 cases," Revue de Médecine Vétérinaire, vol. 152, no. 11, pp. 793-804, 2001.

[35] M. Ferrer and F. Hiraldo, "Human-associated staphylococcal infection in Spanish imperial eagles," Journal of Wildlife Diseases, vol. 31, no. 4, pp. 534-536, 1995.

[36] L. Espino, R. Bérmudez, L. E. Fidalgo, A. González, N. Miño, and M. I. Quiroga, "Meningoencephalitis associated with Staphylococcus warneri in a dog," Journal of Small Animal Practice, vol. 47, no. 10, pp. 598-602, 2006.

[37] S. A. Balajee, M. Weaver, A. Imhof, J. Gribskov, and K. A. Marr, "Aspergillus fumigatus variant with decreased susceptibility to multiple antifungals," Antimicrobial Agents and Chemotherapy, vol. 48 , no. 4 , pp. $1198-1203,2004$

[38] I. F. Keymer, "Diseases of birds of prey," Veterinary Record, vol. 90, no. 21, pp. 579-594, 1972. 

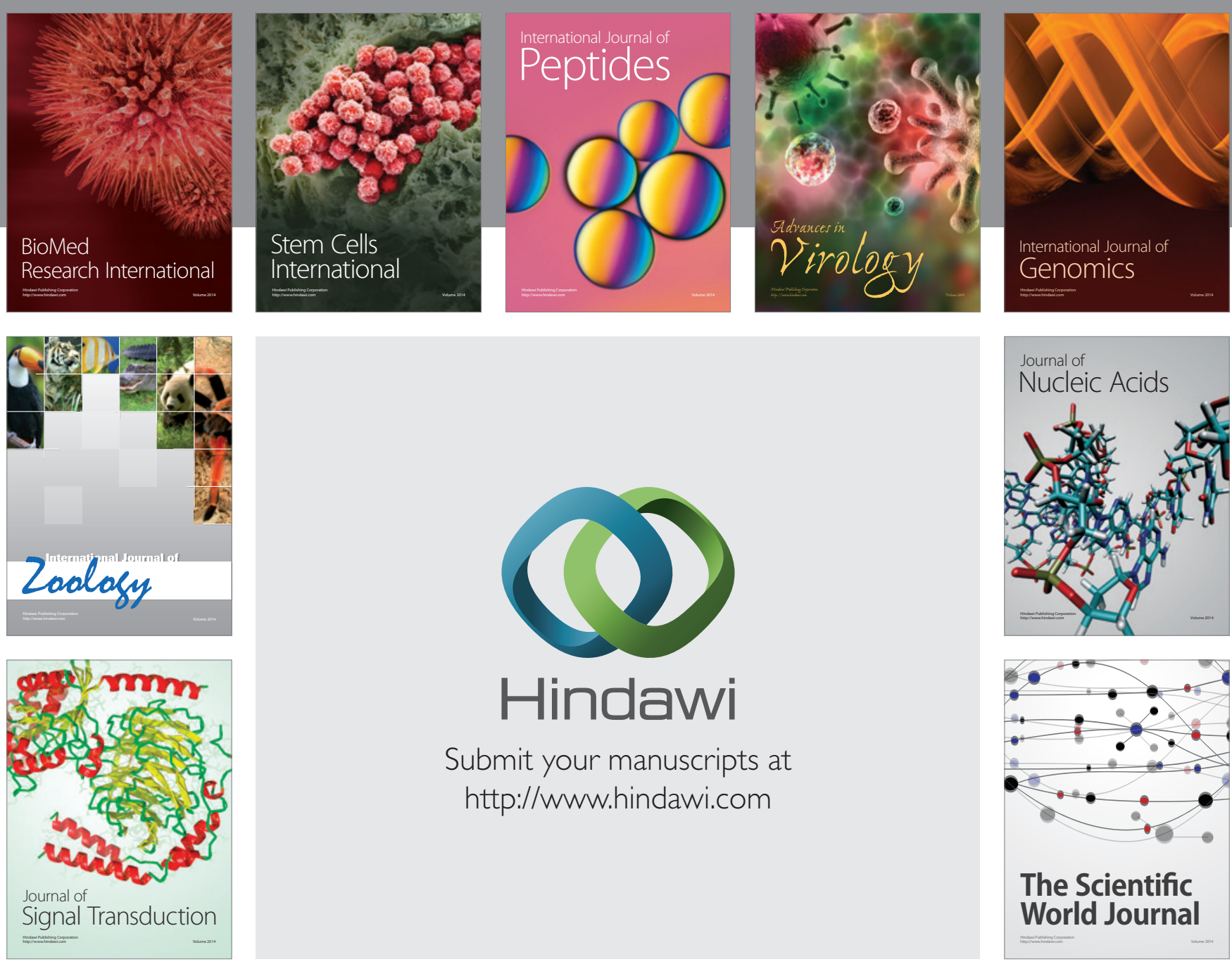

Submit your manuscripts at

http://www.hindawi.com
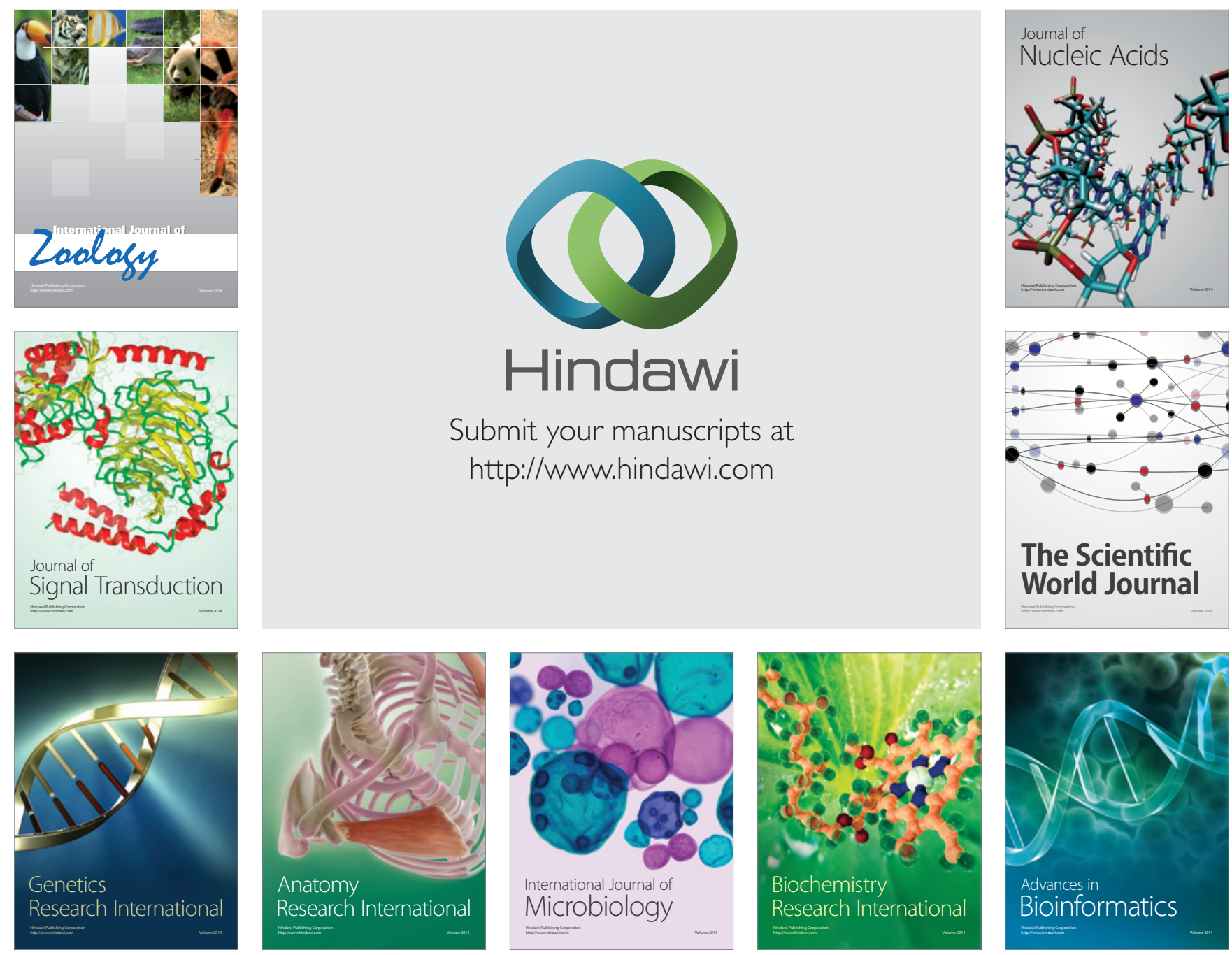

The Scientific World Journal
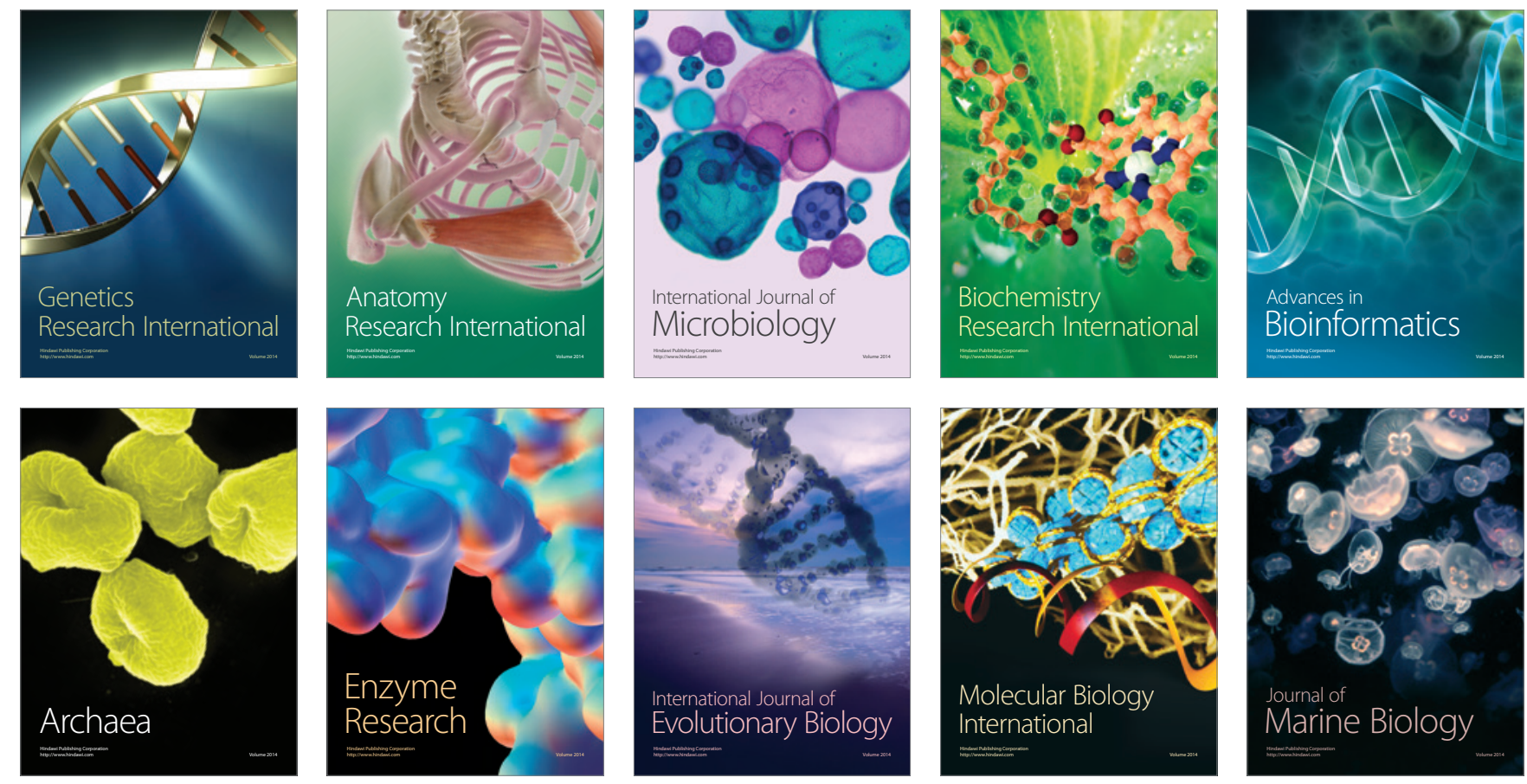